\title{
Review
}

\section{Exploring the mechanisms of renoprotection against progressive glomerulosclerosis}

\author{
By Takashi OITE*1,† \\ (Communicated by Hiroo ImURA, M.J.A.)
}

\begin{abstract}
In this review, I introduce the strategy developed by our laboratory to explore the mechanisms of renoprotection against progressive glomerulosclerosis leading to renal death. First, I describe the experimental rat model in which disturbances of vascular regeneration and glomerular hemodynamics lead to irreversible glomerulosclerosis. Second, I discuss the possible mechanisms determining the progression of glomerulosclerosis and introduce a new imaging system based on intravital confocal laser scanning microscopy. Third, I provide an in-depth review of the regulatory glomerular hemodynamics at the cellular and molecular levels while focusing on the pivotal role of $\mathrm{Ca}^{2+}$-dependent gap junctional intercellular communication in coordinating the behavior of mesangial cells. Last, I show that local delivery of renoprotective agents, in combination with diagnostic imaging of the renal microvasculature, allows the evaluation of the therapeutic effects of angiotensin II receptor and cyclooxygenase activity local blockade on the progression of glomerulosclerosis, which would otherwise lead to renal death.
\end{abstract}

Keywords: chronic kidney disease, progressive glomerululosclerosis, renoprotection, glomerular hemodynamics, in vivo imaging

\section{Introduction}

The number of chronic renal insufficiency patients with need of hemodialysis or renal transplantation has been increasing worldwide. ${ }^{1)}$ In 2003, more than 1 million patients worldwide, of whom 320,000 were in the United States, were receiving maintenance dialysis. ${ }^{2)}$ Similarly, 275,000 patients were receiving maintenance dialysis in Japan in $2007 .{ }^{3)}$ It has been proposed that glomerular hemodynamic changes or glomerular growth responses may promote the development of glomerulosclerosis leading to renal insufficiency, irrespective of etiology.4),5) However, the cellular and molecular mechanisms leading to progressive glomerulosclerosis still remain unclear. The final goal of nephrologists is to

*1 Department of Cellular Physiology, Institute of Nephrology, Niigata University Graduate School of Medical and Dental Sciences, Niigata, Japan.

$\dagger \quad$ Correspondence should be addressed: T. Oite, Department of Cellular Physiology, Institute of Nephrology, Niigata University Graduate School of Medical and Dental Sciences, 1-757 Asahimachi-dori, Niigata 951-8510, Japan (e-mail: oite@med. niigata-u.ac.jp). prevent the progression of glomerulosclerosis leading to renal insufficiency, or to return the sclerotic lesions to the non-perplexed condition in chronically progressive glomerular diseases such as diabetic nephropathy and IgA nephritis. Here, I introduce new insights into the pathogenesis of the disease, based on accumulating evidence provided by others and us. In addition, I present a novel approach for studying local blockade of the renin-angiotensin system (RAS) and the cyclooxygenase-dependent pathway that consists in a confocal laser scanning microscopybased in vivo imaging system.

\section{Establishment of an experimental model of progressive glomerulosclerosis}

Few experimental models exist that mimic irreversible glomerulosclerosis. Of all, the $5 / 6$ ablation model has been the most used and the most reliable one. Many lessons have been learnt from this experimental model; importantly, that glomerular hyperfiltration, hyperfusion, hypertension, and hypertrophy are associated with the progression of glomerulosclerosis. ${ }^{4,5)}$ Other experimental models of progressive glomerulonephrits, such as the acceler- 


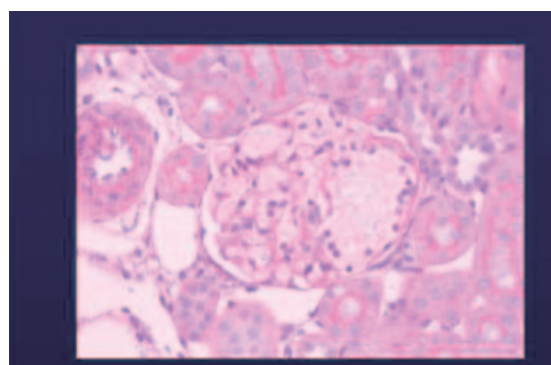

One-kidney group: 3days

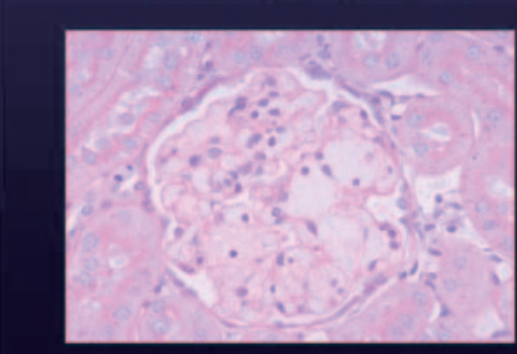

Two-kidney group: 3days

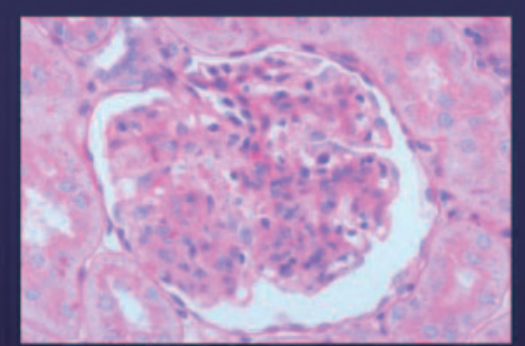

One-kidney group: 14 days

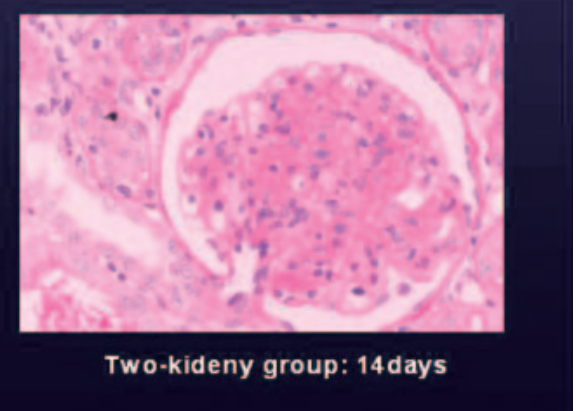

Fig. 1. Light microscopic findings in kidneys from an early stage of the 1-kidney and 2-kidney models. Diffuse mesangiolytic changes with microaneurysmal ballooning were found in both models at day 3. Diffuse mesangial cell proliferation and mesangial matrix expansion were observed at day 14 (PAS stain, 400×).

ated form of anti-glomerular basement membrane nephritis characterized by destructive or crescentic glomerular lesions, differ substantially from the pathohistological features of the gradually accumulating mesangial matrix seen in human diabetic nephropathy and IgA nephropathy, eventually leading to chronic renal insufficiency.

We have originally reported that progressive glomerulosclerosis can be induced in the rat by a 1shot injection of anti-Thy-1.1 monoclonal antibody (antithymocyte serum [ATS]), followed by unilateral nephrectomy. ${ }^{6)}$ The antibody binds to a specific epitope involved in endothelial-mesangial cell contact. ${ }^{7,8)}$ This experimental model has several advantages in the analysis of progression factors leading to irreversible glomerulosclerosis. First, the course of disease between nephrectomized (1-kidney) and shamoperated (2-kidney) groups can be directly compared since the same amount of nephritogenic antibody is bound to each kidney. Second, there is a clear-cut difference in the prognosis of disease between the 1kidney and the 2-kidney models. The 1-kidney model is characterized by progressive glomerulosclerotic lesions with renal insufficiency, while the 2-kidney model is fundamentally reversible, ${ }^{9)}$ as shown in Figs. 1-3. Third, the model can be applied to different rat strains, including the Munich Wistar rats in which many glomeruli are located directly under the vicinal surface of the kidney cortex, ${ }^{10), 11)}$ and genetically modified Sprague Dawley rats, for instance, transgenic rats carrying the enhanced green fluorescent protein (EGFP) transgene. ${ }^{12), 13)}$

\section{Risk factors for progressive glomerulosclerosis}

Maintenance of normal glomerular function requires a well-balanced physiological structure composed of endothelial cells, mesangial cells, and mesangial matrices. Upon glomerular damage, the glomerular function may be impaired before effective repair of glomerular cells and matrix components occurs. We showed that impairment of vascular regeneration is strongly associated with the development of progressive glomerulosclerosis in the 1kidney model, as compared with the 2-kidney model. ${ }^{6}$ Semiquantitative analysis revealed that the capillary density and mRNA expression of platelet/ endothelial cell adhesion molecule (PECAM)-1, vascular cell adhesion molecule (VCAM)-1, and vascular endothelial growth factor (VEGF) in the glomeruli are significantly lower in the 1-kidney group on day 14 (an early stage of glomerulonephritis). On day 84, the 1-kidney group exhibited progressive glomerulosclerotic lesions, followed by a decrease in capillary density. In contrast, the 


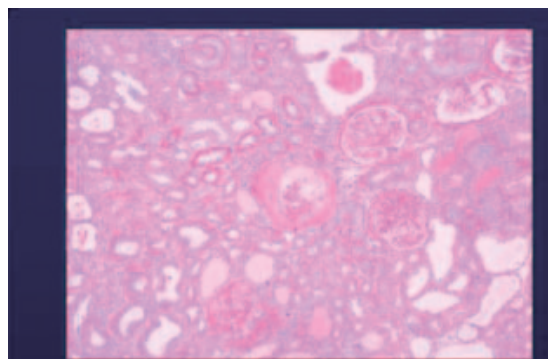

One-kidney group: 84 days

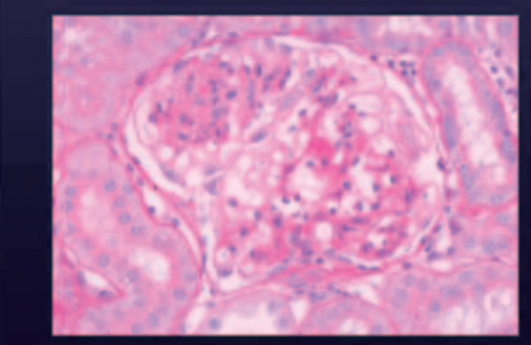

One-kidney group: 84 days

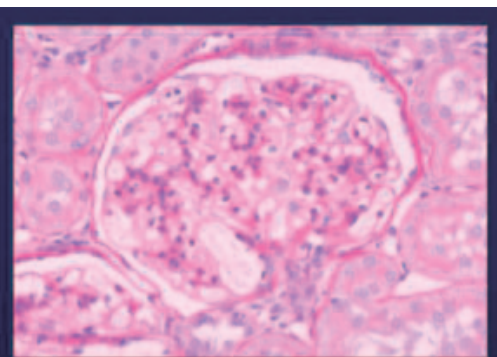

Two-kidney group: 84 days

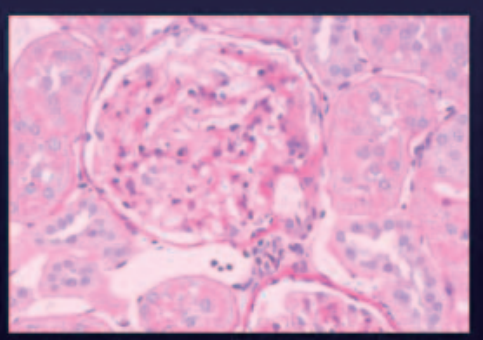

Mephrectomy control group: 84 days

Fig. 2. Light microscopic findings in kidneys from a late stage of the 1-kidney and 2-kidney models. On day 84, the histological changes between the 1-kidney and 2-kidney models were sharply different. Severe mesangial cell proliferation and matrix expansion, often accompanied by sclerotic changes, were observed in the majority of the glomeruli in the 1-kidney model. Diffuse tubular atrophic changes with interstitial cell infiltration were also found. In contrast, only mild mesangial proliferative changes were found in the 2kidney model. No pathological changes were observed in the nephrectomy control group (PAS stain, 50× [upper left panel] and 400× [all other panels]).

\section{Anti-Thy 1 antibody injection}

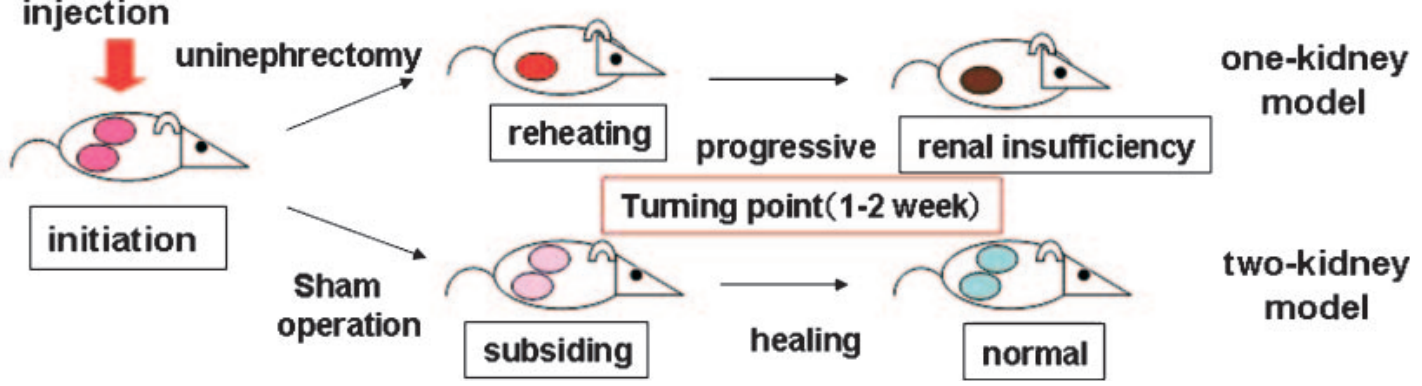

Fig. 3. Scheme showing the disease courses of the 1-kidney and 2-kidney models. Anti-Thy-1 nephritis was induced in rats by intravenous injection of $0.5 \mathrm{mg}$ of the anti-Thy-1.1 monoclonal antibody 1-22-3. Thirty minutes after injection, unilateral nephrectomy of the right kidney was performed (1-kidney model). In the 2-kidney model, a sham operation was performed 30 minutes after injection of the same dose of antibody.

glomerular architecture of the 2-kidney group recovered to an almost normal structure.

Using EGFP-positive bone marrow (BM) chimeric rats, progressive glomerulosclerosis was induced by a 1-shot injection of ATS, followed by unilateral nephrectomy (1-kidney model). ${ }^{13)}$ The progression of glomerulosclerosis was so severe that $75 \%$ of the rats died, presumably of uremia, by 8 weeks after disease induction. To investigate micro- vascular regeneration and glomerulosclerotic lesions in $\mathrm{BM}$ chimeric rats, we examined the recruitment of BM-derived cells in isolated glomeruli and frozen sections. A confocal laser scan microscopic study revealed that BM-derived PECAM- $1^{+}$RECA- $1^{+}$endothelial cells and OX- $7^{+}$mesangial cells which were EGFP-positive and detectable for immunostaining contribute to structurally support the glomerular capillaries during chronicity of the disease. ${ }^{13)}$ 


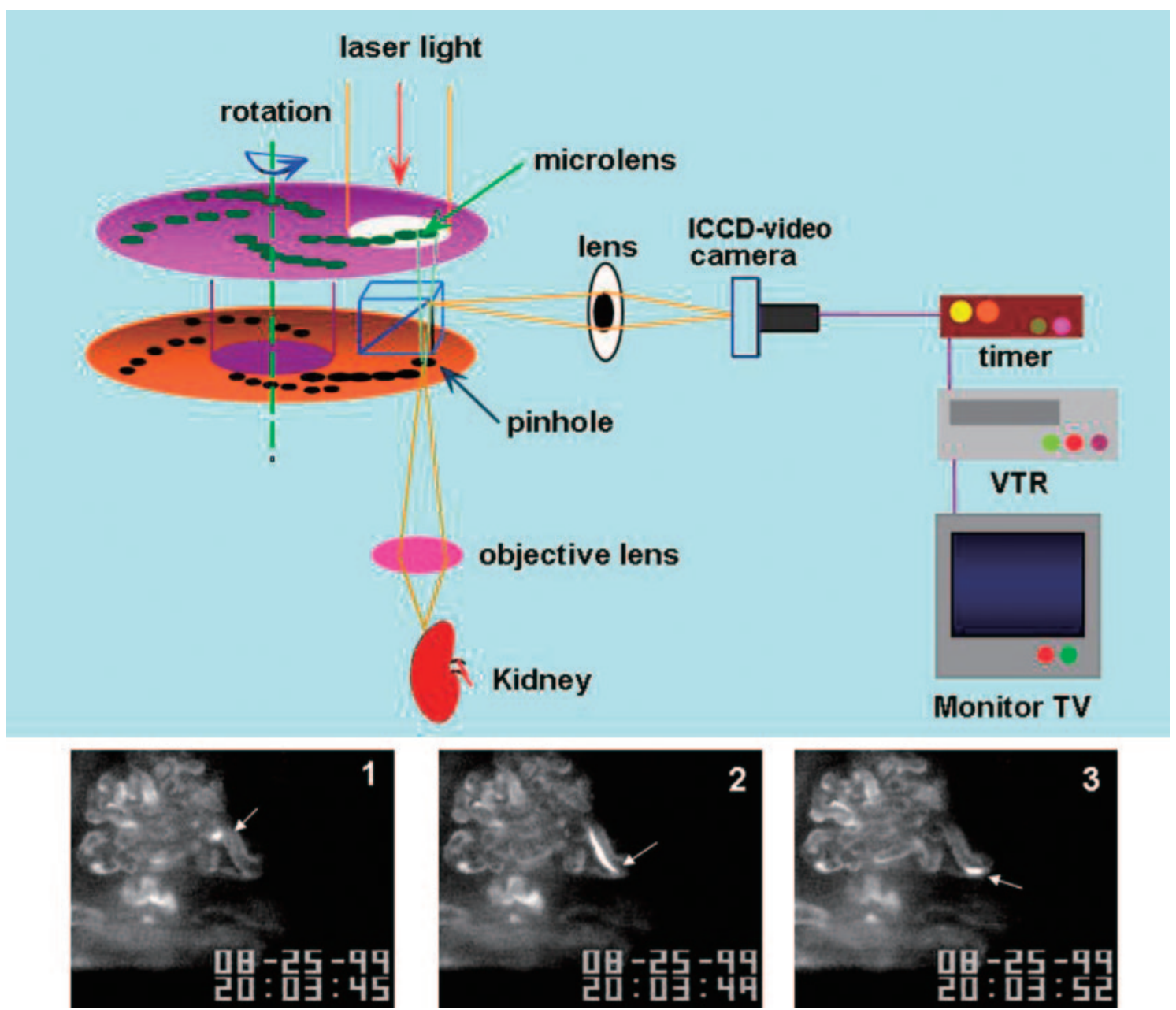

Fig. 4. Scheme of the confocal laser scanning microscope and sequential images showing glomerular microcirculation. A confocal laser scanning microscope (CSU-10; Yokogawa Electric Company, Tokyo, Japan) in combination with an image-intensified charge-coupled device video camera (C2400-89; Hamamatsu Photonics KK, Shizuoka, Japan) was used for real-time observation of renal microcirculation, including glomerular blood flow. The left kidney was exposed by a flank and muscle fascia incision, followed by the analysis of microcirculation from the surface of the kidney. Vascular images were obtained by intravenous injection of a solution of fluorescein isothiocyanate (FITC)-labeled dextran (molecular weight 150,000 Da). To measure blood flow, a batch of autologous red blood cells labeled with FITC was injected into the tail vein. In the lower panels, the sequential images of glomerular microcirculation from a normal Munich Wistar rat are presented. Arrows show the sequential images of the same red blood cell flow. VTR: videotape recorder, TV: television. In addition, the real image of glomerular blood flow can be seen in the additional video movie.

Additional video movie. Representative movie of glomerular blood flow in the normal Munich Wistar rat (http://joi.jlc.jst.go.jp/JSTJ-STAGE/pjab/87.81).

Further, we have attempted to directly observe the hemodynamic events occurring in the glomerular circulation under physiopathological conditions. To that purpose, we have developed an intravital realtime confocal laser scanning microscope system in combination with fluorescent tracer labeling, ${ }^{14)}$ as shown in Fig. 4 and the supplemental video movie. This imaging system has allowed the examination of not only glomerular hemodynamic changes but also of the morphological recovery of the glomerular capillaries after glomerular injury with a noninvasive procedure in Munich Wistar rats. The sequence of hemodynamic changes within the glomeruli was analyzed in the reversible 2-kidney and irreversible 1-kidney ATS models. ${ }^{15}$ ) The determining point in glomerulosclerosis progression occurs during the period from 7 to 14 days after disease induction, when disturbances of local intraglomerular blood flow 

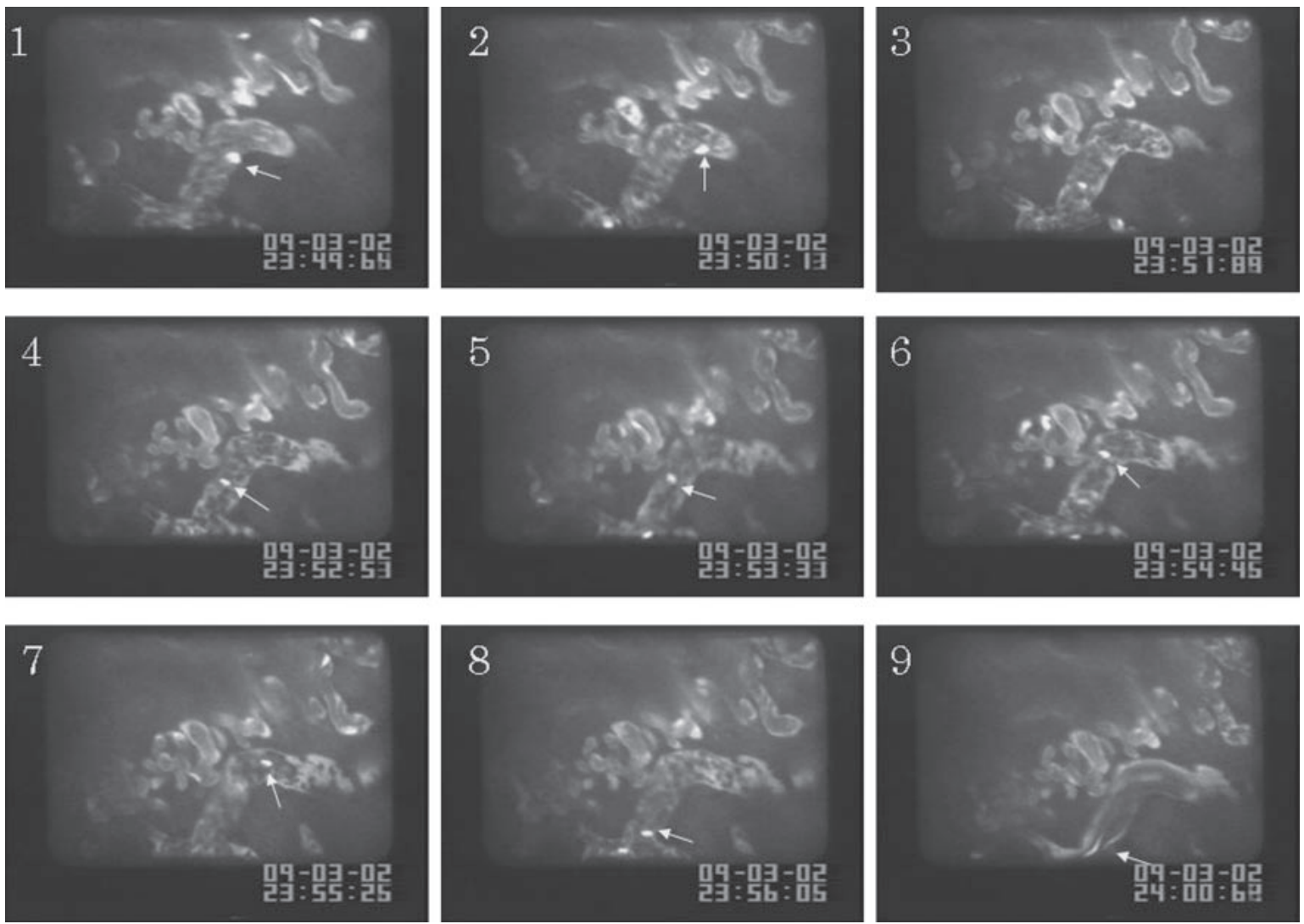

Fig. 5. Sequential images showing abnormal blood flow in the renal interstitium at a late stage of the 1-kidney model. The sequential images of blood flow in the renal interstitial vessel were obtained from a rat with progressive glomerulosclerosis of the one-kidney model, 20 weeks after disease induction. Frames from No. 1 to No. 3 show the sequential images of the same RBC flow, indicating the upward flow. White arrows in frames No. 4 to No. 6 , between the times 52.53 second to 54.45 second, show almost no moving of RBC, indicating the 'stop' flow. Frames from No. 7 to No. 9 show the sequential images of the same RBC flow, indicating the downward flow or 'retrograde' flow.

persist in the 1-kidney group. It should be pointed out that disturbance of local intraglomerular blood flow showing a significant difference in blood flow velocity at two different fixed parts of tufts within a glomerulus, which we called "turbulence of glomerular hemodynamics," far precedes progressive glomerulosclerosis, observed 84 days after disease induction. From the viewpoint of hemodynamics, it is well known that a turbulent flow requires more pressure for a given flow rate than a laminar flow does. ${ }^{16)}$ Therefore, it is reasonable to consider that disturbances in intraglomerular blood flow in the 1-kidney model may induce higher shear and hydrostatic stresses along the glomerular capillary walls in the early phase of renal disease, leading to retardation of capillary repair and, finally, to progressive glomerulosclerosis. Such an abnormal blood flow in the 1-kidney model is aggravated at the late stage of glomerulosclerosis, as shown in the sequential video frames of Fig. 5 in which the images of "stop," "reflow," and "retrograde flow" were caught in the interstitial microvasculature.

\section{Potential roles of mesangial cell-intercellular communication in the juxtaglomerular area}

In the normal glomerulus, the glomerular basement membrane encloses the endocapillary region, which is composed of a capillary lumen, endothelial cells, mesangial cells, and mesangial matrices. This specialized compartment has a passageway through which cell-cell or cell-matrix communicate with the juxtaglomerular area, where afferent and efferent arteries, renin-producing granular cells, and macula densa cells play pivotal roles in the coordinate regulation of glomerular hemodynamics (Fig. 6). Mesangial cells form a tree-like branching network from the hilar site to the glomerular tufts, and connect with each other through gap junctions present in glomerular and extraglomerular mesangial cells (Fig. 6). 


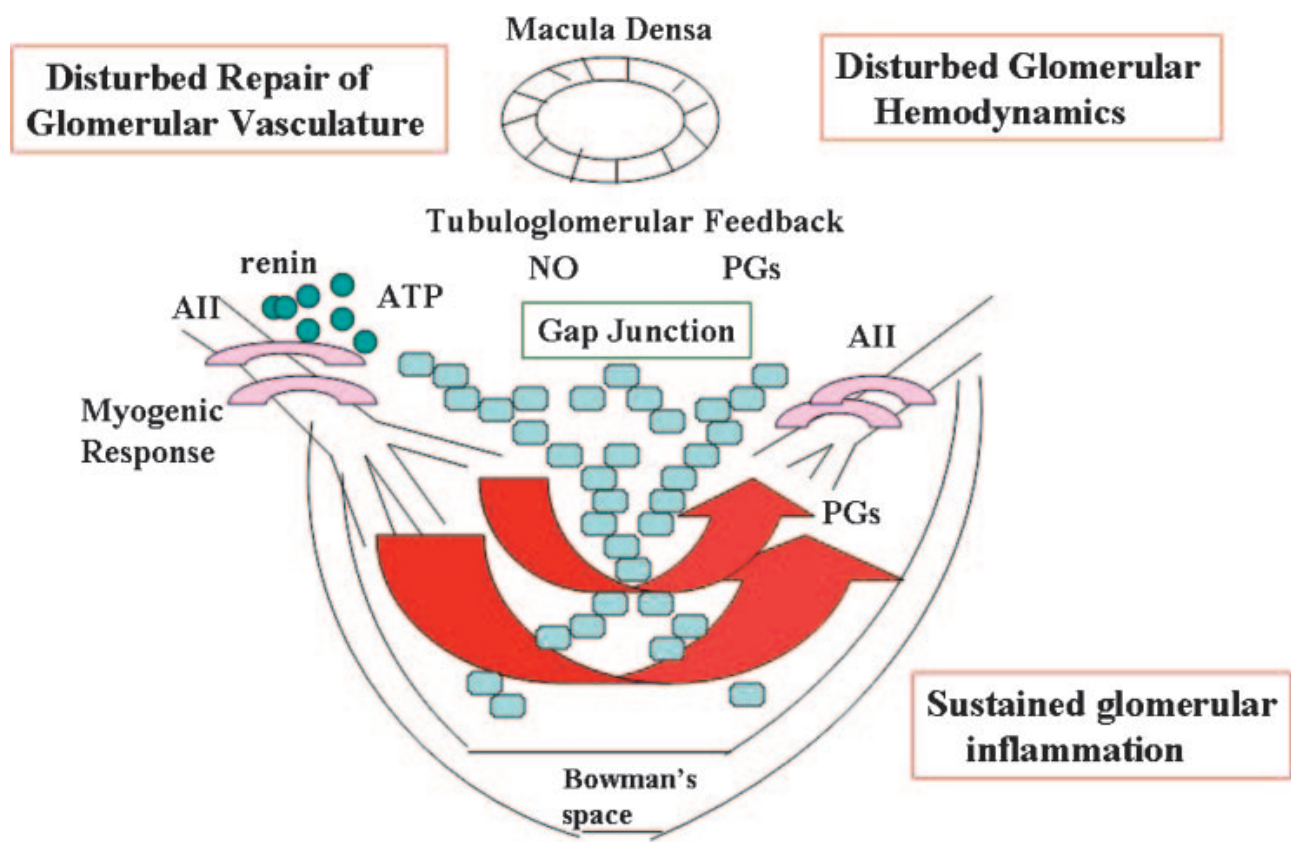

Fig. 6. Mechanisms involved in the progression of glomerulosclerosis. Schema of juxtaglomerular apparatus and glomerulus is shown in addition to the key molecules regulating the glomerular hemodynamics. AII: angiotensin II, ATP: adenosine triphosphate, NO: nitric oxide, PGs: prostaglandins.

Growing evidence suggests that these gap junctions provide the mesangium with the characteristics of a functional syncytium. ${ }^{17)-20)}$ The gap junctions are formed by a family of special proteins, the connexins $(\mathrm{Cx})$. To date, more than 20 different $\mathrm{Cx}$ proteins have been identified. In vitro studies using cultured mesangial cells have confirmed that the gap junctions expressed at cell-cell contacts are functional. ${ }^{17), 18)}$ Microinjection of lucifer yellow into a single mesangial cell resulted in the transmission of the dye through a network of about 10-20 cells. The addition of platelet-derived growth factor (PDGF), known as the most potent mitogen for mesangial cells and an active player in mesangial cell contraction and extracellular matrix synthesis, causes a rapid and transient inhibition of gap junctional intercellular communication. This response to PDGF is remarkably inhibited by treatment of mesangial cells with a phosphatidylinositol 3-kinase (PI3K) inhibitor. PI3K has multiple effects on a variety of signaling molecules associated with protein kinase $\mathrm{C}$ or mitogen-activated protein kinase activation. ${ }^{17)}$ Furthermore, we showed that mechanical stimulation of mesangial cells results in the propagation of a $\mathrm{Ca}^{2+}$ wave through the gap junctions. This $\mathrm{Ca}^{2+}$ wave can be inhibited by the gap junction inhibitor heptanol as well as by a phospholipase $\mathrm{C}$ inhibitor, suggesting a mediating role of inositol triphosphate (IP3) in the initiation and transmission of intercellular $\mathrm{Ca}^{2+}$ signaling. Injection of IP3 into a single mesangial cell causes contraction, not only in the targeted cell but also in the adjacent cells. ${ }^{18)}$

Ideally, the integrated functions of renal microcirculation, propagation of a $\mathrm{Ca}^{2+}$ wave, and coordinated mesangial cell contraction should be examined in in vivo or ex vivo systems. Peti-Peterdi et al. reported very interesting data concerning macula densa sensing and signaling mechanisms by using a refined technique of isolated and microperfused afferent artery-juxta glomerular apparatus-glomerulus. ${ }^{20), 21)}$ Activation of tubuloglomerular feedback by increasing tubular flow rate at the macular densa rapidly produces a significant elevation of intracellular $\mathrm{Ca}^{2+}$ in extraglomerular mesangial cells and renin granular cells. Subsequently, cellto-cell propagation of calcium signaling is observed upstream toward proximal segments of the afferent and adjacent glomeruli, as well as toward intraglomerular elements, including the most distant podocytes. The same $\mathrm{Ca}^{2+}$ wave has been observed in nonperfusing, adjacent glomerulus, causing vasoconstriction and contraction of the glomerular tuft. ${ }^{21}$ )

Using an isolated, perfused kidney model and gap junctional inhibitors such as specific Cx-mimetic 
peptides, we showed very recently that administration of the nonselective gap junction uncoupler $18 \alpha$ glycyrrhetinic acid and the $\mathrm{Cx} 43$ mimetic peptide significantly elevated perfusion pressure while Cx37 and $\mathrm{Cx} 40$ had no effect. ${ }^{22)}$ Using Tie-Cre recombinase and renin-Cre recombinase mice, Wagner et al. reported that endothelial $\mathrm{Cx} 40$ is not essential for the control of systemic blood pressure and renin expression. $^{23)}$ Thus, clarifying the molecular and subcellular mechanisms of $\mathrm{Cx}$-mediated renal microcirculation in the pathophysiological settings awaits future studies, using refined methods of genetic engineering.

\section{Search for therapeutic strategies aimed at enhancing recovery from progressive glomerulosclerosis, focusing on local delivery of drugs}

In clinical situations, drug therapies for glomerulonephritis should be established after the nephritic symptoms are diagnosed. Therefore, it would be important to identify the determining point in the progression of reversible and irreversible glomerulosclerosis, as stressed previously. ${ }^{24)}$ As shown in Fig. 6, we focused on developing therapeutic approaches that target 3 possible mechanisms involved in the determination of the critical point of glomerulosclerosis progression. First, we targeted BM-derived stem cells to stimulate recovery from progressive glomerulosclerosis. ${ }^{25)} \mathrm{EGFP}^{-} \mathrm{BM}$ chimeric rats were infused with BM cells from $\mathrm{EGFP}^{+}$donors once (at day 7) after induction of the 1-kidney model of ATS glomerulonephritis, presumably at the critical point determining the irreversible progression of glomerulosclerosis. BM cell infusion improved renal function and glomerular hemodynamics, and ameliorated histological alterations with reduced glomerular infiltration of macrophages, leading to dramatically reduced mortality. Only 2 of 8 untreated rats survived 12 weeks after disease induction, while 5 of 6 BM cell-infused rats survived until 12 weeks. In the BM cell-infused group, urinary protein excretion, serum creatinine, and blood urea nitrogen levels were significantly lower than in the untreated group from day 8 until 12 weeks after disease induction.

It is now well accepted that substances that block the RAS exert a beneficial effect on the progression of glomerular diseases that would otherwise result in renal insufficiency. ${ }^{26)}$ There is also increasing evidence that intrarenal RAS within glomeruli and interstitial tissues, including renal tubules, is not only involved in physiological proc- esses, but also in pathological conditions, such as vascular remodeling, diabetic nephropathy, and glomerulosclerosis. ${ }^{27-30)}$ Therefore, we attempted to block intrarenal RAS by using of a novel approach that applies renal subcapsular implantation of a collagen sponge as a means to deliver angiotensin II receptor blocker (ARB) locally. ${ }^{31)}$ At day 7 after induction of the 1-kidney model of ATS glomerulonephritis, pellets of type-1 collagen containing phosphate-buffered saline, ARB (Valsartan), angiotensin II, or angiotensin II + ARB, were implanted into the subrenal capsular pocket. Local ARB treatment significantly reduced proteinuria, and ameliorated glomerular pathology, including glomerular matrix expansion and the sclerotic index. In addition, glomerular blood flow levels were also significantly improved compared to the untreated disease group.

Prostaglandins (PGs) modulate renal function, including hemodynamics and water and salt homeostasis. These eicosanoids are formed by the cyclooxygenase (COX)-dependent metabolism of arachidonic acid. COX-2 is constitutively expressed in the macula densa of the juxtaglomerular apparatus and in adjacent epithelial cells of the cortical thick ascending limb of Henle. ${ }^{32)}$ Preliminarily, we examined the pharmacological effects of 2 contrastive agents (a selective COX-2 inhibitor and a prostacyclin analogue, $\mathrm{PGI}_{2}$ ) on the course of the disease in the 1-kidney model of ATS glomerulonephritis. The local delivery of a COX-2 inhibitor at day 7 after disease induction slowed the progression of glomerulosclerosis. In contrast, local administration of $\mathrm{PGI}_{2}$ induces vasodilation and consequent glomerular hyperperfusion. $\mathrm{PGI}_{2}$ is thus considered to render the load of hyperperfusion on the inflamed glomeruli, leading to aggravated glomerular lesion. These results are consistent with our running hypothesis that disturbance of intraglomerular microcirculation is a risk factor for progressive glomerulosclerosis. ${ }^{24)}$ On the other hand, it is known that COX-2 inhibitors induced acute renal failure, similar to that observed with nonselective COX inhibitor. ${ }^{33)}$ In anti-Thy-1 glomerulonephritis, selective COX-2 inhibitors, rofecoxib or celcoxib, impaired glomerular capillary repair after mesangiolysis, probably due to the inhibition of endothelial cell migration, and shape change. ${ }^{34)}$ Compared to the oral administration of selective inhibitor of COX-2, beginning at 18-hour disease induction up to day 5 in this study, we administered a selective inhibitor of COX-2 only once beneath the renal capsule at a fully established stage 
of glomerular inflammation on day 7. The discrepance between these studies could be explained the different timing and pathway of drug delivery.

Diabetic nephropathy is the leading cause of end-stage renal disease in developed countries. ${ }^{35)}$ It has been reported that blocking RAS slows the progression of established diabetic nephropathy. ${ }^{36)-38)}$ To confirm the role of angiotensin II in renal hemodynamics in diabetic rats, we examined the effects of a selective ARB on renal hemodynamic changes in vivo using streptozotocin (STZ)-induced diabetic rats. ${ }^{39)}$ The kidney-to-body weight ratio, glomerular volume, and the diameters of afferent arterioles and efferent arterioles, erythrocyte velocities within glomeruli, volume flow in the glomerular capillary loops in 4-day diabetes mellitus (DM) were significantly higher than in control rats, and these increases were even more pronounced in 28-day DM. The ratio of the diameter of the afferent artery to the diameter of the efferent artery in 28-day DM was markedly increased when compared with control and 4-day DM groups, indicating a continuous increase in internal glomerular pressure with time. Oral administration of ARB for 28 days starting 24 hours after STZ injection resulted in amelioration of all these parameters and significantly decreased proteinuria. Furthermore, subrenal capsular treatment with ARB also reduced urinary protein excretion. In addition, local delivery of ARB attenuated monocyte/ macrophage infiltration into the glomeruli and the enhanced glomerular expression of endothelial nitric oxide (NO) synthesis both at the mRNA and protein levels. ${ }^{40)}$ These results indicate that ARB acts as an anti-inflammatory drug during the early phases of STZ-induced diabetic nephropathy. Activation of $\mathrm{NF}-\kappa \mathrm{B}$, a well-known player in inflammation and the immune response, can be measured as the increase in expression of the p65 subunit of $\mathrm{NF}-\kappa \mathrm{B}$, and its translocation from the cytoplasm to the nucleus in both tubular epithelial and glomerular cells from the diabetic kidney. Local ARB treatment induced a reduction in p65 nuclear localization and staining intensity. In Zucker fatty rats, the calcium-dependent protease calpain plays a role in reducing endothelial nitric oxide synthase activity and NO availability, leading to endothelial dysfunction and vascular inflammation. ${ }^{41)}$ In our study, glomerular expression of $145 / 150-\mathrm{kDa}$ spectrin breakdown products, specific of calpain activation, was dramatically increased in diabetic rats. Remarkably, the protein expression reverted to the normal level after local ARB treatment.

\section{Concluding remarks}

State-of-the-art strategies are now available to delay or prevent the potentially irreversible progression of glomerular diseases to renal insufficiency. Taking into account the current knowledge described in this review article, I would like to draw some concluding remarks. Local delivery of renoprotective agents such as RAS and COX-2 inhibitors can be applied to successfully control glomerular hemodynamics and attenuate glomerular inflammation although further study will be needed for clinical use. Furthermore, noninvasive diagnostic devices for measuring glomerular function parameters, including hemodynamics, permeability, and contractibility, should be developed to objectively diagnose the stage of progression and to examine the pharmacological effect of established or newly developed drugs. For example, refined photonic probes and imaging systems that have an excellent specificity and high resolution have promising clinical applications.

\section{Acknowledgments}

I thank all the colleagues who have cooperated with research projects in our laboratory. I also acknowledge Drs. A. Vogt and T. Wagai for their continuous encouragements. This work was supported by research grants $(04670199,06670215$, A11770597, A13770598, 10670988, 12671032) from the Ministry of Education, Science, Sports and Culture, a grant for The Promotion of Niigata University Research Projection, and grants from Novartis Pharmaceuticals and Nippon Shinyaku Co., Ltd.

\section{References}

1) Lysaght, M.J. (2002) Maintenance dialysis population dynamics: current trends and long-term implication. J. Am. Soc. Nephrol. 13, S37-S40.

2) Nolan, C.R. (2005) Strategies for improving longterm survival in patients with ESRD. J. Am. Soc. Nephrol. 16, S120-S127.

3) Nakai, S., Masakane, I., Shigematsu, T., Hamano, T., Yamagata, K., Watanabe, Y., Itami, N., Ogata, S., Kimata, N., Shinoda, T., Syouji, T., Suzuki, K., Taniguchi, M., Tsuchida, K., Nakamoto, H., Nishi, S., Nishi, H., Hashimoto, S., Hasegawa, T., Hanafusa, N., Fujii, N., Marubayashi, S., Morita, O., Wakai, K., Wada, A., Iseki, K. and Tsubakihara, Y. (2008) An overview of regular dialysis treatment in Japan as 31 December 2007. Ther. Apher. Dial. 13, 457504.

4) Hostetter, T.H., Olson, J.L., Rennke, H.G., 
Venkatachalam, M.A. and Brenner, B.M. (1981) Hyperfiltration in Remnant nephrons: a potentially adverse response to renal ablation. Am. J. Physiol. 241, F85-F93.

5) Fogo, A.B. and Kon, V. (1997) Pathophysiology of progressive renal disease. In Immunologic Renal Diseases (eds. Neilson, E.G. and Couser, W.G.). Lippincott-Raven, Philadelphia/New York, pp. 683726.

6) Wada, Y., Morioka, T., Oyanagi-Tanaka, Y., Yao, J., Suzuki, Y., Gejyo, F., Arakawa, M. and Oite, T. (2002) Impairment of vascular regeneration proceeds progressive glomerulosclerosis in anti-Thy-1 glomerulonephritis. Kidney Int. 61, 432-443.

7) Morioka, T., Yao, J., Suzuki, Y. and Oite, T. (2004) The characterization of a specific Thy-1 molecular epitope expressed on rat mesangial cells. Kidney Int. 66, 2214-2223.

8) Oite, T., Saito, M., Suzuki, Y., Arii, T., Morioka, T. and Shimizu, F. (1996) A specific Thy-1 molecular epitope expressed on rat mesangial cells. Exp. Nephrol. 4, 350-360.

9) Nakayama, H., Oite, T., Kawachi, H., Morioka, T., Kobayashi, H., Orikasa, M., Arakawa, M. and Shimizu, F. (1998) Comparative nephritogenicity of two monoclonal antibodies of rat Thy-1.1 molecule. Nephron 78, 453-463.

10) Steinhausen, M., Zimmerhackl, B., Thederan, H., Dussel, R., Parekh, N., Esslomger, H.U., von Hagens, G., Komitowski, D. and Dallenbach, F.D. (1981) Intraglomerular microcirculation: measurements of single glomerular loop flow in rats. Kidney Int. 20, 230-239.

11) Hackbarth, H., Buttner, D., Jarck, D., Pothmann, M., Messow, C. and Gartner, K. (1983) Distribution of glomeruli in the renal cortex of Munich Wistar Fromter (MWF) rats. Ren. Physiol. 6, 6371 .

12) Okabe, M., Ikawa, M., Kominami, K., Nakanishi, T. and Nishimune, Y. (1997) 'Green mice' as a source of ubiquitous green cells. FEBS Lett. 407, 313319 .

13) Ikarashi, K., Li, B., Suwa, M., Kawamura, K., Morioka, T., Yao, J., Khan, F., Uchiyama, M. and Oite, T. (2005) Bone marrow cells contribute to regeneration of glomerular endothelial cells. Kidney Int. 67, 1925-1933.

14) Oyanagi-Tanaka, Y., Yao, J., Wada, Y., Morioka, T., Suzuki, Y., Gejyo, F., Arakawa, M. and Oite, T. (2001) Real time observation of hemodynamic changes in glomerular aneurysms induced by antiThy-1 antibody. Kidney Int. 59, 252-259.

15) Kawamura, K., Okada, S., Li, B., Suwa, M., Yao, J., Morioka, T., Gejyo, F. and Oite, T. (2006) Turbulence of glomerular hemodynamics involved in progressive glomerulosclerosis. Kidney Int. 69, 1792-1798.

16) Berne, R.M. and Levy, M.N. (2000) Hemodynamics. In Principles of Physiology. 3rd edition (eds. Berne, R.M. and Levy, M.N.). Mosby, St. Louis, pp. 227-236.

17) Yao, J., Morioka, T. and Oite, T. (2000) Require- ment for PI3-kinase in PDGF-induced disruption of gap junctional intercellular communication and phosphorylation of connexin 43 in mesangial cells. Kidney Int. 31, 1915-1926.

18) Yao, J., Morioka, T., Li, B. and Oite, T. (2002) Coordination of mesangial cell contraction by gap junction-mediated intercellular $\mathrm{Ca}^{2+}$ wave. J. Am. Soc. Nephrol. 13, 2018-2026.

19) Yao, J., Suwa, M., Li, B., Kawamura, K., Morioka, T. and Oite, T. (2003) ATP-dependent mechanisms for coordination of intercellular $\mathrm{Ca}^{2+}$ signaling and renin secretion in rat juxtaglomerular cells. Circ. Res. 93, 338-345.

20) Peti-Peterdi, J. (2006) Calcium wave of tubuloglomerular feedback. Am. J. Physiol. Renal Physiol. 291, F473-F480.

21) Peti-Peterdi, J. and Harris, R.C. (2010) Macula densa sensing and signaling mechanisms of renin release. J. Am. Soc. Nephrol. 21, 1093-1096.

22) Piao, H., Sato, A., Nozawa, Y., Sun, W., Morioka, T. and Oite, T. Effects of connexin-mimetic peptides on perfusion pressure in response to phenylephrine in isolated, perfused rat kidneys. Clin. Exp. Nephrol. (in press).

23) Wagner, C., Jobs, A., Schweda, F., Kurtz, L., Kurt, B., Lopez, M.L.S., Gomez, R.A., van Veen, T.A., de Wit, C. and Kurtz, A. (2010) Selective deletion of connexin 40 in renin-producing cells impairs renal baroreceptor function and is associated with arterial hypertension. Kidney Int. 78, 762-768.

24) Oite, T. and Yao, J. (2009) Disturbance of glomerular hemodynamics: a risk factor determining progression of glomerular diseases? J. Nephrol. 22, 196-202.

25) Li, B., Morioka, T., Uchiyama, M. and Oite, T. (2006) Bone marrow cell infusion ameliorates progressive glomerulosclerosis in an experimental rat model. Kidney Int. 69, 323-330.

26) Brenner, B.M. (2002) Remission of renal disease: recounting the challenge, acquiring the goal. J. Clin. Invest. 110, 1753-1758.

27) Wilkes, B.M. (1987) Reduced glomerular angiotensin II receptor density in diabetes mellitus in the rat: time course and mechanism. Endocrinology 120, 1291-1298.

28) O'Brien, R.C., Cooper, M.E., Jerums, G. and Doyle, A.E. (1993) The effects of perindopril and triple therapy in a normotensive model of diabetic nephropathy. Diabetes 42, 604-609.

29) Dechow, C., Morath, C., Peters, J., Lehrke, I., Waldherr, R., Haxsen, V., Ritz, E. and Wagner, J. (2001) Effects of all-trans retinoic acid on reninangiotensin system in rats with experimental nephritis. Am. J. Physiol. Renal Physiol. 281, F909-F919.

30) Ballermann, B.J., Skorecki, K.L. and Brenner, B.M. (2001) Reduced glomerular angiotensin II receptor density in early untreated diabetes mellitus in rat. Am. J. Physiol. 247, F110-F116.

31) Mahmood, J., Khan, F., Okada, S., Kumagai, N., Morioka, T. and Oite, T. (2006) Local delivery of angiotensin receptor blocker into the kidney 
ameliorates progression of experimental glomerulonephritis. Kidney Int. 70, 1591-1598.

32) Harris, R.C., McKanna, J.A., Akai, Y., Jacobson, H.R., Dubois, R.N. and Breyer, M.D. (1994) Cyclooxigenase-2 is associated with the macula densa of rat kidney and increases with salt restriction. J. Clin. Invest. 94, 2504-2510.

33) Perazella, M.A. and Eras, J. (2000) Are selective COX-2 inhibitors nephrotoxic? Am. J. Kidney Dis. 35, 937-940.

34) Kitahara, M., Eitner, F., Ostendorf, T., Kunter, U., Janssen, U., Westenfeld, R., Matsui, K., Kerjaschki, D. and Floege, J. (2002) Selective cyclooxygenase-2 inhibition impairs glomerular capillary healing in experimental glomerulonephritis. J. Am. Soc. Nephrol. 13, 1261-1270.

35) Williams, M.E. (2010) Diabetic CKD/ESRD 2010: a progress report? Semin. Dial. 23, 129-133.

36) Ruilope, L.M. (1997) Renoprotection and reninangiotensin system blockade in diabetes mellitus. Am. J. Hypertens. 10, 325S-331S.

37) Lewis, E.J., Hunsicker, L.G., Clarke, W.R., Berl, T., Pohl, M.A., Lewis, J.B., Ritz, E., Atkins, R.C., Rohde, R. and Raz, I. for the Collaborative Study Group (2001) Renoprotective effect of the angiotensin-receptor antagonist irbesartan in patients with nephropathy due to type 2 diabetes.
N. Engl. J. Med. 345, 851-860.

38) Jacobsen, P., Andersen, S., Jensen, B.R. and Parving, H.H. (2003) Additive effect of ACE inhibition and angiotensin II receptor blocker in type I diabetic nephropathy. J. Am. Soc. Nephrol. 14, 992-999.

39) Li, B., Yao, J., Kawamura, K., Oyanagi-Tanaka, Y., Hoshiyama, M., Morioka, T., Gejyo, F., Uchiyama, M. and Oite, T. (2004) Real-time observation of glomerular hemodynamic changes in diabetic rats: effects of insulin and ARB. Kidney Int. 66, 19391948.

40) Kamal, F., Yanakieva-Georgieva, N., Piao, H., Morioka, T. and Oite, T. (2010) Local delivery of angiotensin II receptor blockers into the kidney passively attenuates inflammatory reactions during the early phases of streptozotoci-induced diabetic nephropathy through inhibition of calpain activity. Nephron, Exp. Nephrol. 115, e69-e79.

41) DeVriese, A.S., Stoenoiu, M.S., Elger, M., Devuyst, O., Vanholder, R., Kriz, W. and Lameire, N.H. (2001) Diabetes-induced microvascular dysfunction in the hydronephrotic kidney: role of nitric oxide. Kidney Int. 60, 202-210.

(Received Nov. 24, 2010; accepted Jan. 31, 2011)

\section{Profile}

Takashi Oite was born in 1945. He graduated Niigata University School of Medicine in 1974 and started his research career in 1975 with studies on the experimental glomerulonephritis at the Institute of Nephrology, Niigata University School of Medicine. He obtained Doctor of Philosophy (Ph.D.) in 1979. The title of thesis is "Masugi nephritis in $\mathrm{T}$ cell depleted state. Influence of adult thymectomy and anti-thymocyte serum". He had studied as a scholarship holder of Alexander von Humboldt foundation, with Professor Arnold VOGT, in Freiburg, West Germany (1979-1981). He was promoted to Professor and Director at the Department of Cellular Physiology, Institute of Nephrology, Niigata University Graduate School of Medical and Dental Sciences, in 1996. He has extended his research to explore the pathogenesis of progressive

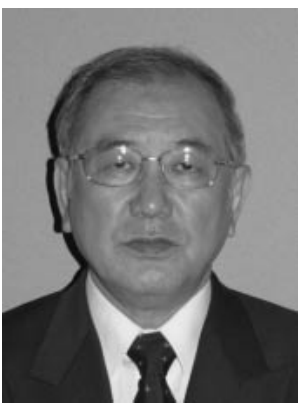
glomerulosclerosis and therapeutic approach for halting the progression of glomerulosclerosis leading to renal death. He was awarded The Naito Foundation Natural Science Scholarship in 1997, Japan Pathology Award and Kidney Foundation Award for Science Research in 2006. 